where it was necessary to give $2 \frac{1}{4} \mathrm{gr}$. every six twenty-three years of age. Occupation, drug clerk. days for several weeks in order to keep the symp- Family history not obtained.

toms under control.

Duration of treatment. - As to the length of time over which the treatment should extend, it is customary in this country to give a course of the injections for two years and then, after a rest of a few months, reinstitute treatment for six months or a year. Recently certain French syphilographers have maintained that syphilis is insufficiently treated and that there is a relation between the insufficient treatment and the socalled parasyphilitic affections, - general paralysis of the insane and tabes dorsalis. The apparent dependency of these parasyphilitic disorders upon syphilis as a determining etiological factor, has led the veteran Fournier to recommend a course of treatment which is based upon the fact that the parasyphilitic lesions very seldom develop before the sixth year of the disease and most frequently appear during the ninth and tenth years following the initial lesion. This method of treatment Fournier has termed, " Méthode des cures mercurielles à termes tardifs." In brief, it consists of a thorough mercurial treatment covering the first two years of the disease. At the end of this time treatment is discontinued and if no symptoms appear, the patient is allowed what Byrom Bramwell has aptly called " a period of therapeutic repose" for two years, during which time no mercury is administered: then during the fifth year the patient receives a course of mercury lasting one year. The patient is again allowed to go without mercury until the latter part of the seventh or the beginning of the eighth year at which time the final course of mercury is administered. This method is yet in its infancy; Fournier has claimed nothing for it; he has merely offered it as a suggestion. From a pathological point of view it seems very plausible, and in spite of the disheartening attempts to prevent the occurrence of these diseases by the usual treatment covering three years or less, it is deserving of a thorough trial before being condemned simply because the less prolonged treatment has been so frequently ineffectual in preventing these diseases.

$$
\text { BIBLIOGRA PHY. }
$$

Bramwell, B.: Clinical Studies, New Series, vol. iv, part II, p. 116. Bernhardt, $\dot{W}_{\text {. }}$ American Medicine, Oct. 31, 1903, p. 707 . Heidingsfeld, $\dot{M}$. L.: Journal American Medical Association, vol. $\mathrm{xl}, \mathrm{p} .1626$.

Pezolli: Wiener klinische Wochenschrift, vol. xv, p. 1360

Sinclair: New York Medical Journal and Philadelphia Medical Journal, vol. lxxx, p. 778 .

Gottheil, W. S.: Ibid., vol. Ixxxiii, p. 1340.

\section{EXTERNAL EYE INFLAMMATIONS OF DOUBTFUL ORIGIN.}

BY H. GLover LANG Worthy, M.D., DUBUQUe, IOWA.

CASE I. Bilateral Orbital Cellulitis and Exophthalmus of Obscure Origin, Simulating Cavernous Sinus Thrombosis and Double Frontal Involvement; Infecting Organism, probably Pneumococcus.

On Aug. 24, 1906, there was admitted to the Massachusetts Charitable Eye and Ear Infirmary on the aural service of Dr. Edward M. Plummer, a young man,
Past history. - Has had the usual " children's diseases." Said to have had "blood poisoning " of right forearm when twelve years old from an abrasion of the index finger.

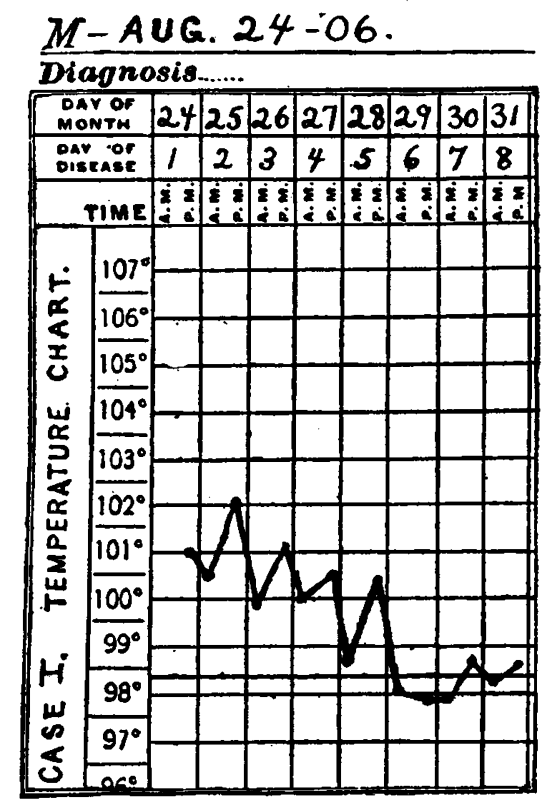

Present illness. - Two and one half days before coming under observation noticed a slight swelling to the outer edge of both orbital margins. The following day the eyes shared in the extension, becoming reddened and painful. There was some discharge. He was able to work during the day although suffering from increasing lachrymation, blurring of vision, pain and headache. The subcutaneous tissues below both eyes became puffy and reddened. Towards night the men at the store remarked that his lids were swollen and "eyes stuck out." General condition seemed fairly good in spite of the virulence of the local infection. He was ignorant as to the cause of the trouble, had been handling drugs and also used a towel common to all.

On Aug. 23, the case was first seen by Dr. H. C. Parker and referred to the House. There seemed a reasonable doubt as to whether the condition was a beginning thrombosis of the cavernous sinuses or the result of disease in the accessory nasal sinuses. There was an appreciable exophthalmus of both eyes, chemosis of the lids, and fever. No vomiting, chills or dizziness.

Physical examination. - Well developed and nourished. Moderate prostration. Chemosis of lids of both eyes and exophthalmus. Great ocular injection, conjunctivæ swollen to the extent as to overlap the cornca in places. Cornea clear. Pupil dilated from atropine. Iris, good color. There is a stringy mucofibrinous discharge from both eyes. Fundi negative. Vision: right eye 20-70, left eye 20-50. Diminution in sight due principally to the discharge adhering to the surface of the cornea. The skin immediately below both eyes is puffy and reddened but no line of demarcation. No apparent external connection between the inflammation of each orbit, the skin over the nose being normal. No tenderness over either frontal sinus. White count, 12,000 . Temperature $101^{\circ} \mathrm{F}$., pulse 100 , 
and respirations 28 . Nose, throat, lungs, abdomen and ears negative. Smear showed the xerosis bacillus, a nonpathogenic organism in the eye. Cultures were taken of the discharge. In spite of the local condition the patient's mind was clear and he could walk easily and naturally about the ward. The chief complaint was one of local discomfort. The appearance of the middle third of the face was that of disfigurement from an exceedingly acute infection of unknown origin. The treatment of eye cleanliness and frequent ice compresses was carried out by Dr. D. W. Drury, the Aural House Surgeon.

Aug. 25. The diagnosis is still uncertain. Developing erysipelas, thrombosis of the cavernous sinuses and acute involvement of both frontals have each in turn been considered. Poisoning from bites or drugs was discarded. There is slight bilateral exophthalmus, edema of the lids and great injection and swelling of the conjunctivæ. Temperature, $102^{\circ}$ F., pulse, 115 . Very little prostration. The x-ray plates taken yesterday show no involvement of frontal, ethmoids or antrum, on either side. There seemed no reason to suspect a caries of the body of the sphenoid. Cultures showed chiefly the pneumococcus.

Aug. 26. Exophthalmus has disappeared. Slight prostration. Mind clear.

Aug. 28. Edema of the lids, swelling and injection of ocular conjunctiva almost gone. Temperature normal. Fundi negative. Vision with glass normal.

Aug. 31. Eyes white and quiet and apparently normal. Discharged well.

If we accept as the characteristic feature of phlegmonous inflammation a relatively slight alteration of the surface with diffuse swelling and hardness of the deeper tissues, and the temperature chart of a purulent fever with slight remissions, this case must fall under such a nomenclature. These conditions sometimes subside without operative interference. The clinical picture may vary with the location.

The mischief started undoubtedly as a conjunctivitis of pneumococcus origin with a stringy mucous discharge. Temporarily neglected, it soon proved to be exceedingly troublesome. We are told that one of the first features which Sternberg himself noticed was the great variation in the virulence of this organism. Subcutaneous inoculations with cultures of the pneumococcus will cause usually only a local reaction, while injections into the peritoneal cavity of a rabbit will produce a rapidly fatal septicemia.

Once started the infection followed lines of perhaps low resistance in this particular case and quickly involved the cellulo-fatty tissue of the orbits. Of course, the infection may have been a mixed one, associated with either the streptococcus or some of the intermediate bacteria. There was no history of trauma.

Beginning facial erysipelas seemed to me at first the most plausible explanation, but the subsequent course of disease showed that I was wrong.

Acute poisoning would hardly have given exophthalmus.

With an infectious process in a region anatomically drained by the cavernous sinuses one is naturally on the lookout for such a catastrophe. The condition is, however, always associated with the most severe cerebral symptoms, and by the time both eyes are affected the patient is moribund. Death is also the invariable accompaniment of cavernous sinus thrombosis. ${ }^{1}$

As orbital inflammation may be the result of empyema of the frontal, ethmoids or antrum, without demonstrable intranasal signs the x-ray was invaluable in settling that important question.

Exophthalmus coming on a week or two after initial attacks of influenza with and without pneumonic lesions, have been reported, but they do not seem applicable here. A most careful examination for sphenoidal disease was negative.

I am aware that the theories offered in this paper as to the causative factors of the local trouble are a presentation of doubts. One would suppose that Tenon's capsule should offer an effectual barrier towards infection anteriorly. It is easy to say that the condition must have started intranasally but such was not the fact.

Cases of bilateral orbital phlegmon are rare.

CASE II. Acute Bilateral Edema of the Eyelids of Unknown Etiology; Question of Angio-Neurotic Edema or Double Frontal Sinusitis.

On Oct. 18, 1905, a young man, eighteen years of age, was admitted to the Infirmary on the aural service of Dr. E. M. Plummer. Birthplace, Sweden. Understood and spoke English imperfectly.

The following history was secured: No previous eye trouble. Six days before coming to the hospital noticed that the lids of the right eye were badly swollen and painful. This morning the left eyelids also became involved. Much local discomfort. Thought he might have been bitten by mosquitoes. Said to have had a discharge from the left nostril.

Physical examination. - Marked redness and swelling of the lids of both eyes. No definite point of infection through the skin could be found, even with the aid of a hand lens. Chemosis occupied chiefly the outer two-thirds of the lids. Cornea clear. No ocular injection. No tenderness over either frontal sinus. Right nostril, mucous membranes not reddened. Slight hypersecretion, no pus. Turbinates not especially congested. Deviation of septum to right. Left nostril, nothing abnormal found. X-ray taken of accessory nasal sinuses.

This evening there is a small inflammatory swelling on the back of the right hand almost identical to that of the lids. The appearance of a third area of redness and edema on a distant portion of the body was most helpful as indicating the unlikelihood of any trouble in the frontal sinuses.

Oct. 20. Swelling of the lids of both eyes has almost subsided. Redness and edema of still another circumscribed area nearly encircling the right forearm has appeared. No temperature. Local itching and discomfort. X-ray showed no trouble in the sinuses as was expected.

Oct. 24. No swelling or redness about the eyes, right hand or forearm. Discharged well.

The etiology of the local disturbance was obscure. The case seemed to tally best under that type of trophoneurosis known as angioneurotic edema. It was an affection of local

1 In a paper on a " Proposed Operative Measure for Thrombosis of the Cavernous Sinus" (The Laryngoscope,July, 1906), an endeavor was made to show that the cavernous sinus could be drained by removing the inner wall of the orbit and anterior and lateral wall removing the inner wall of the orbit and anterior and lateral wal of one sphenoidal cavity. Attempts at draining the sinus by following a Gasserian ganglion resection route have twice been given a trial by Hartley and Knapp, Arch. of Ophthalmology, 1900, May, 1902. 
edematous swellings, more or less limited in extent and of transient duration. The edema appeared suddenly. There was no temperature or gastro-intestinal colic. No family history of a like trouble could be obtained.

Snell ${ }^{2}$ reports a case of acute edema of the eyelids of both eyes in a pork butcher coming on a few hours after dressing a pig which contained a large number of intestinal worms. The swelling rapidly subsided and was well in a few days. There was no exophthalmus or ocular injection.

There would seem to be an affinity between the one presented by Snell and Case II, inasmuch as they might both have been caused by the action of unknown toxic agents.

$$
\text { BIBLIOGRAPHY. }
$$

Bacon, W. 'T.: A Case of Secondary Carcinoma of the Sphenoidal Bacon, W. Tavities Aausing Ocular Paralysis and Destruction of Sight. Proc. Conn. Med. Soc., Hartford, 1882 , n. s., ii, 44-47.

Baumgarten, E.: Affection des Sinus Sphenoidalis. Pest. med.chir. Presse, Budapest, 1891, xxvii, 225.

Berger, E.: Les Symptômes des Maladies du Sinus Sphénoïdal. Berger, E.: Les Symptômes des Maladies du Sin
Rev. mens. de Laryngol., Paris, 1888, viii, 397-401.

Berger (E.) und Tyrman, J.: Die Krankheiten der KeilbeinBerger (E.) und Tyrman, J.: Die Krankheiten der Keilbein-
Höhle und des Siebbein-Labyrinthes und ihre Beziehungen zu den Höhle und des Siebbein-Labyrinthes und ihre Begi

Erkrankungen des Seh-organs. Wiesbaden, 1886.

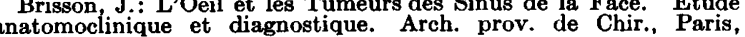
anatomoclinique et

1900, ix, 756-789. Bryan, J. H.: Diseases of the Sphenoidal Sinuses in Relation to
Diseases of the Eye. Jour. Am. Med. Asso., Chicago, 1899, xxxiii, Diseases of the Eye. Jour. Am. Med. Asso., Chicago, 1899, xxxiii, Bull, C. S.: Some Points in the Symptomatology, Pathology and
Treatment of Diseases of the Sinuses Adjacent and Secondary to the Treatment of Diseases of the Sinuses Adjacent

Caldwell. G. W.: Diseases of the Pneumatic Sinuses of the Nose, and their Relation to Certain Affections of the Eye. Med. Rec., N. Y., 1893, xliii, 425-427.

Church and Peterson: Nervous and Mental Diseases. 3d ed. 1901.

Day, E. W.: Report of a Case of Caries of the Sphenoid Bone. Jour. Am. Med. Asso., Chicago, 1895, xxv, 890-892.

Desbrieres and Grenier: Spontaneous Emphysema of the Lids.

L'Ophth. Prov., May, 1905.

De Schweinitz, G. E.: Diseases of the Eye. 1903, 4th ed.

Duane, A.: Symptoms Presented by the Different Bacteriological

Types of Acute Conjunctivitis. 'Trans. Am. Ophth. Soc., 1905.

Fuchs, Ernest: Lehrbuch der Augenheilkunde, 1905.

Greene, D. W.: A Case of Unrecognized Empyema of the Right

Sphenoidal Sinus; Great Exophthalmus and Divergence of Right

Cyeball; Extensive Edema of Right Side of Face and
Autopsy. Ophth. Rec., Chicago, 1897, vi, 346-350.

Grossmann, L.: [Disturbances of Vision from Diseases of Nose and Accessory Cavities of Sinus Frontalis and Sinus Sphenoidalis.] Gyogyaszat, Budapest, 1893, xxxv, 111; 122. Trans. [Abstr.] Pest. med.-chir. Presse, Budapest, 1894, xxx, 245 472 .

Gruening, E.: Orbital Cellulitis, with Empyema of Ethmoid and Frontal Sinuses. Trans. Am. Ophth. Soc.. 1905.

Grunwald, L.: Diseases of the Mouth, Pharynx and Nose. 1903, 2d ed. Translated by Newcomb.

Hansell, H. F.: A Case of Acute Loss of Vision from Disease of the Ethmoid and Sphenoid Cavities. Phila. Polyclinic, 1896, v, 201-205. Med. and Surg. Rep., Phila., 189, lxxv, 101-105.

Harlan, G. C.: Distention of Nasal Accessory Sinuses Involving the Orbit. 'Trans. Am. Ophth. Soc. 1900.

Langworthy, H. G.: Cavernous Sinus Thrombosis in Children Following Mastoid Infiammation. The Laryngoscope, Oct., 1906. Holmes, C. R.: The Sphenoidal cavity and Its Relation to the Fye. Arch. Ophth., N. Y., 1896, xxv, 460-477.

Jackson, G. T.: Diseases of the Skin. 3d ed., 1899.

Kaplan: Le Sinus Sphénoidal comme Voie d'Infection Intracranienne et Orbitaire. Paris, 1891.

Knapp, H.: Mucocele and Empyema of the Ethmoidal Cells and Sphenoidal Sinuses Causing Displacement of Eyeball; their Operation from the Eyeball. Arch. Otol., N. Y., 1893, xxii, 313-328. Zeitschr. f. Ohrenh. Wiesb., 1893-94, xxv, 217-231.

Lapersonne, F. de: An Optic Neuritis Associated with Sphenoidal Sinusitis and Diseases of the Posterior Parts of the Nasal Fossa. L'Écho Méd. du Nord., Sept. 17, 1899; J. Laryng., Lond., 1900, xv, 49; Ophth. Clinique 1899, nr. 12; Arch. d'Ophth., Paris, 1899. Lagrange, F.: Traité des Tumeurs de l'Oeil. Paris, 1903

Laurens, G.: La Chirurgie des Sinus de la Face dans ses Rapports avec la Chirurgie de l'Orbite. XIIIe Cong. Internat.

Sect. de Laryngol., 1900. Paris, 1901, C. R., 107-113. Ibid.: Relations des Maladies du Nez et de ses Annexes avec le
Maladies des Yeux. Gaz. d. hôp. Paris, 1895, lxvii, 1021-1031.

Lewin (Berlin) and Guillery (Cöhn): Effects of Medicinal Drug and of Poisons on the Eye. Aug. Hirschwald, 1905

Mallory and Wright: Pathological Technique. 3d ed., p. 138, 1904.

McEwen, W.: Diseases of the Brain and Spinal Cord. 1893

Oppenheim and Mayer: Diseases of the Nervous System. 2d ed., 1904.

Jack, F. E.: Case of Cavernous Sinus Thrombosis Following Grippe; Autopsy by Verhoeff, F. H. Trans. Am. Ophth. Soc., p. 545,1902 .

2 Acute Edema of the Eyelids, Snell, S.: Am. Jour. of Ophth., June, 1906..
Osler, Wm.: Practice of Medicine. 1900, 3d ed.

Patterson, M. F.: The Influences of Diseases of the Nasal Accessory Sinuses on the Eye. Tr. Iowa State Med. Soc., Cedar Rapids, 1897, xv, 59-70; Med. Times, N. Y., 1898, xxvi, 136-138. Posey: Eye Symptoms Connected with Diseases of the Accessory Sinuses of the Nose. Jour. Eye, Ear and Throat Dis., March, 1905.
Raymond, P.: Carie de Sphénoĩde. Méningite de la base. Raymond, P.: Carie de Sphénoïde. Méningite de la base.
Thrombose des Sinus Coenneux, Exophthalmie Double Rapide. Thrombose des Sinus Coenneux, Exophthalmi Risley, S. D.: Displacement of the Eyeball by Disease of the Scholz: Caries des Keilbeins; Eitersenkung durch die Fossa

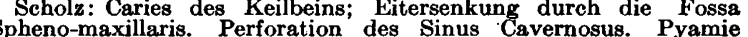
Spheno-maxillaris. Perforation des Sinus Cavern
und Meningitis. Berl. klin. Woch. 1872, ix, 516.

Snell, S.: Acute Edema of Eyelids. Am. Jour. Ophth., June, 1906.

Werner, L.: Symmetrical Tumors of the Orbits in a Case of Acute Leukemia with Rapidly Fatal Result. Ophth. Soc. United Kingdom, June 8, 1905.

Willette, J. E.: Differential Diagnosis of Exophthalmos. Penn. Wed. Jour., June, 1905.

Williamson, R. T.: A Case of Bilateral Ophthalmoplegia and Neuroparalytic Ophthalmia due to Sarcoma of the Sphenoid Bone. ed. Chron., Manchester, 1891, xiv, 417-421.

Grant, D.: A Case of Frontal Headache Depending on Sphenoidal vii.

\section{Elinical \$Department.}

\section{RUPTURE OF THE MALE URINARY BLADDER.*}

by benjamin brabson Categ, M.D., Knoxville, tenn.

IN Annals of Surgery for December, 1905, appears a well-written and interesting article by Dr. Horwitz, of Philadelphia, on "Rupture of the Male Urinary Bladder." He gives an exhaustive dissertation on the subdivisions, pathology, and the mechanism of the different kinds of rupture of this organ, and cites reports of like injury as occurring in the practice of a number of distinguished surgeons. On account of the scarcity of the literature on this subject, there being an average of four cases annually reported to the literature, he admits no well regulated line of treatment in " Rupture of the Male Urinary Bladder" is as yet laid down to the medical profession. Therefore, on account of the relative scarcity of rupture of the male urinary bladder, it appeared to me that each accident of this kind that comes under the notice of surgeons should receive due consideration at the hands of the profession, together with any complications that may appear, and the treatment thereof, so that the data thus collected may enable those who practise surgery to formulate a plan of action to meet the exigencies of each case of injury of the male urinary bladder.

For this reason I wish to make report of a case of rupture of the male urinary bladder that came under my observation. I shall deal only with the extra-peritoneal variety.

On June 30, 1905, I was called to Cambell's Station in consultation with Drs. J. A. Mourfield and R. M. Tillery to see Charles Boring, a lad of fourteen years, who presented the following history:

On the morning of the accident, which was June 28 , 1905, he left home on horseback about 8 A.M., to go to the village, some three miles away, to attend to some business. Thinking to shorten his trip, he took an unfrequented path through the woods. Some three or four hours after he had left home his family saw him returning, leading his horse, and acting in a dazed sort of way. He could give no account of himself, except after starting from home he left the main road * Read before the Knox County, Tenn., Medical Society Sept. 27, 1906 . 